\title{
Introduction
}

\section{The Editors}

This edition of European Comic Art has no overarching theme, but a number of questions recur in the work of our contributors, including the nonlinearity of the comics reading process, the power of the graphic line to satirise and demythologise, and the complex issue of readership and interpretation. We are very happy to be able to include an interview with the young Bangalore-based comics artist Kaveri Gopalakrishnan, who gives us insights into the small-press Indian comics scene and discusses her own themes, influences and techniques.

Narratologist Raphaël Baroni considers certain of the formal characteristics of comics, the coexistence on the page of a linear, sequential narrative with a tabular arrangement of panels that can be viewed simultaneously, as well as the possibility of including multilinear paths through the page, within the framework of 'unnatural narratology'. He argues that while the variable sjuzhet, or nonlinear storytelling process, tends to be confined in literature to experimental works, it is a basic property of the medium in comics, to the extent that a purely linear comics narrative (like one accessed one frame at a time via a phone screen) is 'unnatural'. Conversely, he claims, comics have rarely exploited time paradoxes at the level of the fabula, or story events, even in the case of time travel, which in comics most often takes the form of the 'extraordinary journey', a pretext for the graphic imagination of artists rather than an exercise in disrupting temporal logic. We may look to Watchmen as an exception: Dr Manhattan's simultaneous awareness of past, present and future seems decidedly unnatural, but, points out Baroni, it corresponds to the normal reading process for a comics reader. Moreover, this comic may expand our notion of what a 'natural' experience of time can be, given our experience of gazing at stars that die before their light reaches us, or simply of looking at old photographs.

The article by Benoit Crucifix and Gert Meesters is based on a journey that is undoubtedly extraordinary, Arsène Schrauwen's voyage 
to the Congo, as recounted by his grandson, Olivier Schrauwen. The unreliable narrator declines to conform to a recent 'graphic novel' variant of the journey theme that takes the form of reportage or (auto)biographical account, exorcising intergenerational guilt by careful work of documentation. The reader rapidly loses faith in Schrauwen's bizarre and fantastical account as having any basis in factual events. However, Crucifix and Meesters show how Schrauwen's absurdist depiction of his hapless grandfather's misadventures has resonance as a metaphor for the Belgian colonial experience - for example, his irrational fear that parasites may invade his body, and his consequent attempt to render his bodily orifices inviolate, replicates the attempts by settlers to avoid contamination by the local culture. Crucifix and Meesters also analyse Schrauwen's tangled and ironical relationship with the Franco-Belgian legacy, steeped as it is in colonial mythology. They show how he draws upon its tropes, graphic styles and colour palettes as raw material to be worked over in a highly self-reflexive way. More generally, he plays upon the mechanisms of the comics page by exacerbating its potential for displaying itself as two-dimensional pattern, to the point where the illusion of a three-dimensional diegetic world is suspended. Finally, they argue that by depicting Arsène translating random lines into images, Schauwen foregrounds his 'aesthetic of bricolage', and thereby shows how discourses and stereotypes may be reappropriated and turned into something new.

David Morgan's article on eighteenth-century satirical prints points to the role that popular imagery has always played in creating a sense of nationhood, even, or especially, when they mercilessly lampoon the head of state. The graphic line of James Gillray and his contemporaries ridiculed the Hanoverian monarchs on grounds of their boorishness, sexual appetites and political meddling, but, Morgan argues, the symbolism of the Crown as signifier of the body politic remained unaffected by this virulent mockery of the king's 'body natural'. In support of this thesis, he draws upon a variety of both well-known and lesserknown prints. In engaging with the work of scholars who have proposed interpretations of some of the material that he analyses, Morgan points to some of the difficulties involved in understanding the reception of these prints in the eighteenth century: the educated bourgeois who actually purchased them are likely to have been familiar with the visual tropes of classical mythology, but a more popular readership who gained access to them through other methods of circulation (in print shop windows, for example) would not have brought the same set of 
visual references. The explosion of political satire may well have fostered a sense of collective national identity, but any attempt to decode the sometimes ambiguous 'ideology' of the satirists' work has to grapple with the complexities of 'public opinion' when the 'public' was a highly diverse one.

Thierry Groensteen also considers the question of individual responses to a comic in a return to the concept of tressage or 'braiding' that he elaborated in his major 1999 work Système de la bande dessinée [The System of Comics]. Braiding refers to links between panels, based on formal, iconic or semantic correspondences, woven throughout an album and operating over and above the narrative sequence. The currency that the concept has gained is evident from the fact that Baroni mentions braiding in his article in this issue as one of the ways in which the linear, narrative-driven reading of the page is constantly in tension with the reader's awareness of a network of nonlinear connections. Groensteen emphasises in his article that braiding is not to be found in every comic, and that where it is present, it may pass unnoticed by the reader without detracting from the intelligibility of the work, although with the loss of some depth of interpretation. Groensteen sets out to correct some misunderstandings to which the term has given rise. He points out that the repetition of elements, such as the reappearance of characters, does not count as a braiding effect, since it is necessary for the simple functionality of the narrative: braiding is always a supplementary effect, and one that enriches and enhances our understanding of the work. There are, moreover, degrees of braiding: at a minimum, only two elements may be involved, but the chain can be much longer, and the effect of the braiding can be slight or dramatic. He then exemplifies the concept both from a recent and a nineteenthcentury comic, arguing that its powerful symbolic resonance in the latter indicates that it is part of the very definition of the medium.

Our interview with Kaveri Gopalakrishnan begins with a reflection on her childhood reading of comics, Indian and American, and her responses to the roles assigned to female characters (which she did not, at that stage, explicitly formulate as a question of gender politics: that would come later). She goes on to talk about the specific artists (notably Craig Thompson) who motivated her decision to become a comics creator, and how she has been able to draw on her training in animation in designing her comics. She discusses the process of arriving at the sound effects that are such a striking feature of her work and, more generally, the communication of sensory experience. The interview 
moves on to the question of creating art in a complex political context where different sensibilities must be negotiated, but Gopalakrishnan nonetheless affirms the pleasure of ridiculing the moral policing that tries to keep women in their place. Gopalakrishnan also responds to questions about collaborative working and her use of Instagram, noting the particular kind of contact that it promotes. Lastly, she gives us a rundown of her many current projects. The most important question is kept to the very end, and we will not include a spoiler here.

Finally, we have a change of personnel to report. Mark McKinney, one of our founding editors, will be leaving European Comic Art at the end of 2016. Mark's contribution to the journal has been incalculable, and we have greatly valued his immense scholarship, thoughtful judgement, professionalism and wit. He will be much missed. A new member of the editorial team will be taking over in 2017, and we are delighted to be able to announce that this is Anne Magnussen from the University of Southern Denmark, whose reputation as a comics theorist and whose experience as an editor are very well-known among scholars of comic art. We are also losing Catherine Labio, who has been a phenomenal Reviews Editor, upon whose efficiency and flair we have greatly relied, and who has built up the reviews section of the journal into a substantial and valuable contribution to comics studies. Starting in 2017, this role will be shared by Armelle Blin-Rolland from the University of Bangor and Catriona McLeod from the University of London Institute in Paris. These two comics scholars bring expertise in a number of key areas, including adaptation and gender, and we are very fortunate that they have agreed to join the ECA team. 